\title{
ORIENTATION OF TRB-WEST MEGALITHIC MONUMENTS
}

\section{A. CÉSAR GONZÁLEZ-GARCÍA, Instituto de Astrofísica de Canarias, and LOURDES COSTA-FERRER, La Laguna, Tenerife}

Funnel Beaker, or Trichterrandbecher (TRB), people introduced the Neolithic economy along with a characteristic pottery into parts of the North European Plains. ${ }^{1}$ The TRB area has been divided into several groups reflecting the differences found in the material culture. ${ }^{2}$ The remains found in the northern parts of the Netherlands and the northwest of Germany belong to the TRB-West Group (Figure 1). These remains have been dated in calibrated radiocarbon dates from 3400 B.C. to about 2800 B.C. ${ }^{3}$

The TRB people built a variety of megalithic structures for burial purposes. Passage graves or GrossSteingräber are the most common, but there are others. ${ }^{4}$ In a GrossSteingräb a near-rectangular chamber bordered by large orthostats forms the tomb. Dry stone fills the space between these boulders. In a number of monuments either one or two pairs of stones form a passage, and these are located in the middle of one of the long sides. The chamber is always much larger than the entrance. A tumulus covered the T-shaped megalithic structure, and on several occasions a kerb was laid surrounding this tumulus. ${ }^{5}$

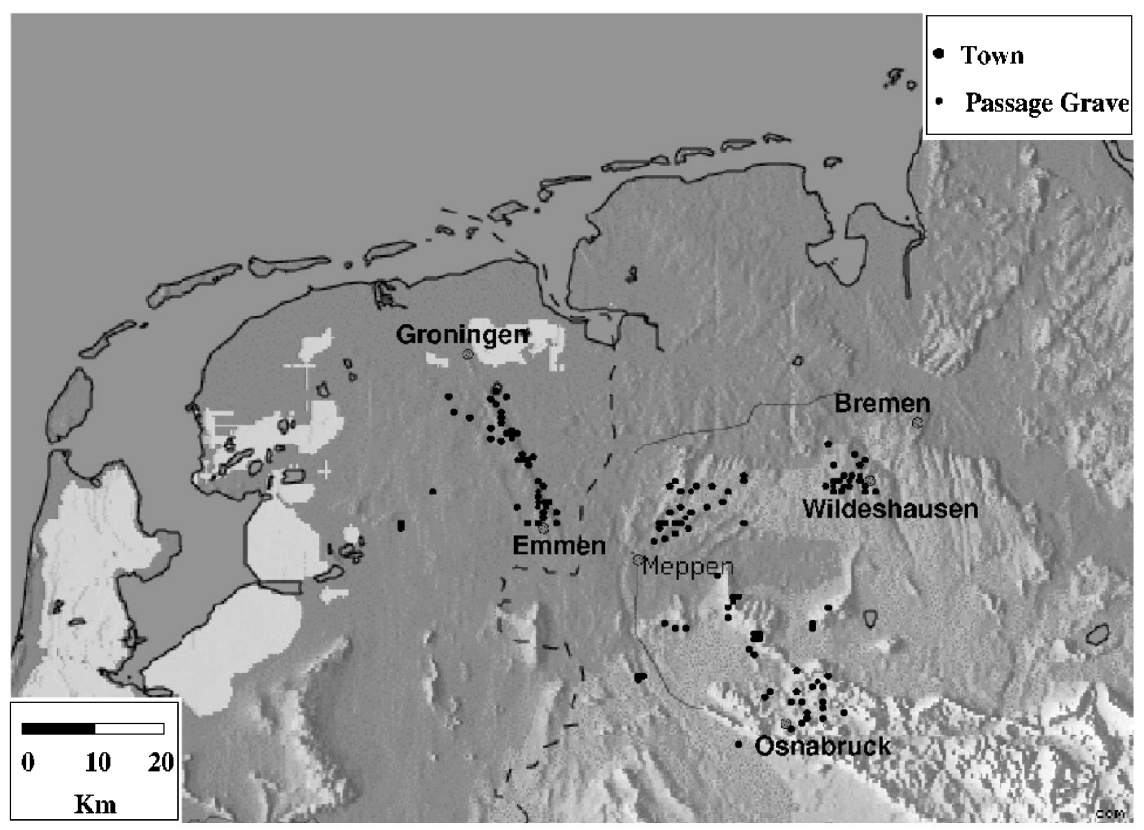

FIG. 1. Distribution of the megalithic monuments in the TRB-West group. Filled circles indicate measured monuments.

0021-8286/06/3704-0417/\$10.00 @ 2006 Science History Publications Ltd 
The TRB-West region is flat and sandy with gentle elevations. These hills are the remains of glacial activity during the Pleistocene and are composed of moraine sands and granite boulders. Most of the monuments are built from these boulders and so are located close to these elevations. ${ }^{6}$

Figure 2 shows examples of the monuments we are dealing with. Many of them appear in groups. The megalithic structures are commonly called Hunebedden (in Dutch) or Hünenbetten ${ }^{7}$ (in German), that is, 'Giant's Bed', and this term gives a flavour of the many legends and tales that have been associated with these monuments since ancient times. Sadly, many of them have disappeared or are now in a poor state: the stones of a number of Hünenbetten were used to lay the foundations of churches in the Middle Ages, or for the construction of roads and dams in more recent times. ${ }^{8}$ However, more than a hundred of these megalithic monuments have survived in this area and we have attempted to measure a statistically significant population.

\section{TRB-West}

We have measured the orientation of 163 megalithic monuments west of the river Wesser, in three campaigns. In the first, we measured the orientations of those in the Netherlands. ${ }^{9}$ In the second, we obtained data for 42 monuments around the areas of Meppen and Wildeshausen in Lower Saxony (Germany). ${ }^{10}$ Finally, in May 2005 we obtained data for a further 69 monuments close to Osnabrïck and the other two areas in Germany. Table 1 lists the data for all the monuments measured in Germany, while the figures in this paper present the results for all 163 TRB-West monuments (Germany plus the Netherlands).

We measured the orientations with a compass furnished with a clinometer. The accuracy of the measurements is about $\frac{1}{2}^{\circ}$ in azimuth and $1^{\circ}$ in altitude, and we calibrated magnetic azimuth readings by taking readings of the sun's azimuth. We measured the azimuth of the tomb along the axis of the chamber in both directions. We also measured the orientation of the passage where this was possible. In total we have passage measurements for 63 monuments, or $40 \%$ of the total of 163 .

Table 1 gives the number according to Sprockhoff, ${ }^{11}$ a name or place of location, and the measured azimuth. We present the eastern/southern value of the azimuth of the chamber in this table (see below). The table also gives the altitude of the horizon. In many cases the megaliths are in the middle of a forest so that the tree cover makes measuring the altitude of the horizon difficult; this is indicated in the table by a dashed line. The altitude of the horizon is generally low, therefore we have used values of $0^{\circ}$ for the determination of the declinations listed in Table 1 .

The 111 German Hünenbetten share common characteristics with the 52 Hunebedden measured in the Netherlands. ${ }^{12}$ They present a general east-west pattern of orientation of the chamber. The entrances are always located in the south or east side of the monuments.

The chamber azimuth for the 163 monuments in Germany and the Netherlands are shown in Figure 3, upper left. Both ends are considered. There is a general pattern of 

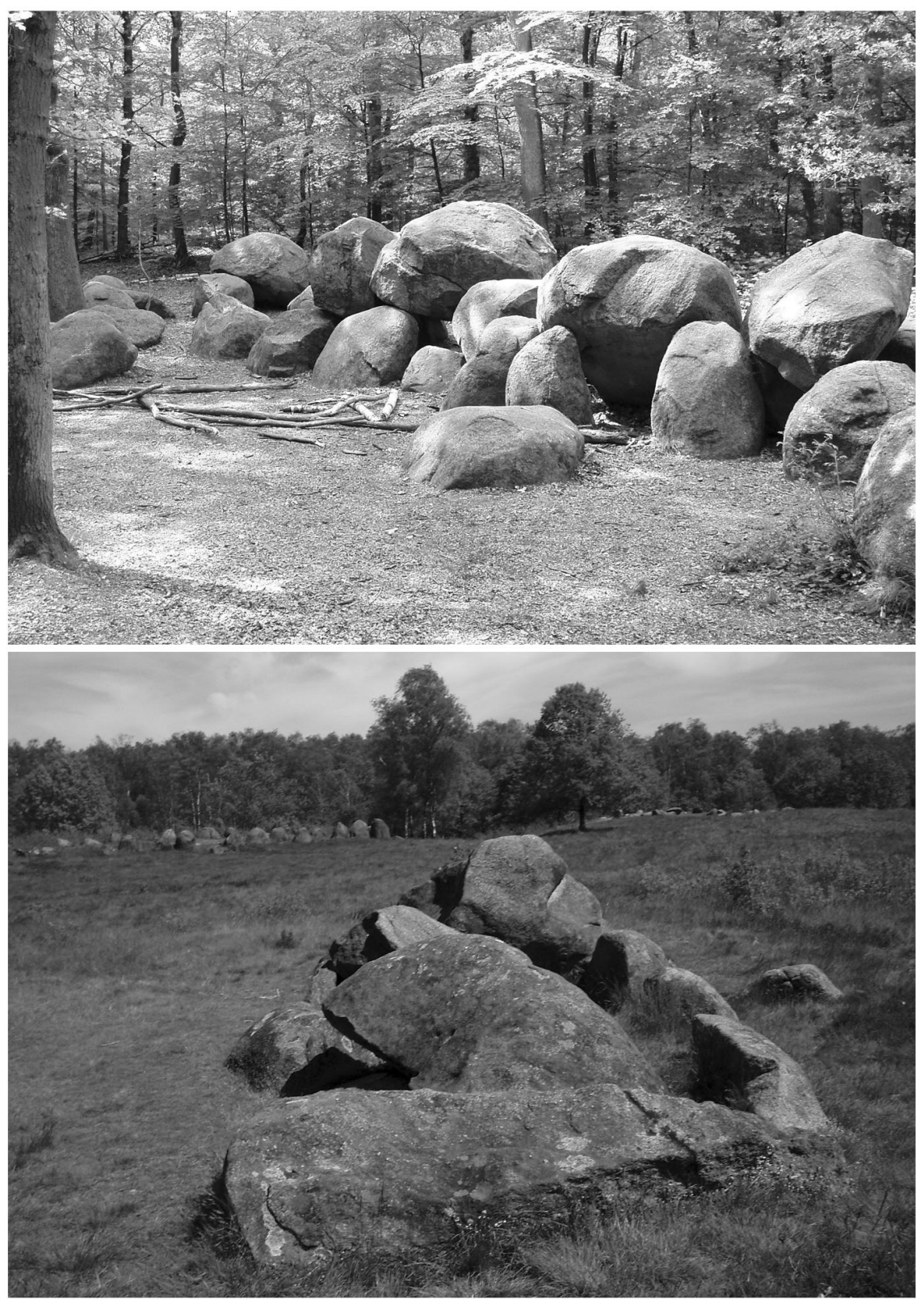

FIG. 2. (above) The Hünenbet 'Grosse Sloopsteine' (Sprockhoff 984) near Osnabrück displays the elongated structure of the chamber, the capstones, and the short passage (to the left of the picture); (below) 'Glaner Braut' I, II and III (Sprockhoff 948, 949 and 950) near Wildeshausen; this is an example of a group of several megaliths located in a small area. 
TABLE 1. 111 measured megaliths in the German TRB-West region. The columns give Sprockhoff's number, a name or location, the chamber azimuth (A), altitude of the horizon (h) where possible, the declination, passage azimuth (pass.) where possible, and the geographic coordinates (lat.; long.), in degrees.

\begin{tabular}{|c|c|}
\hline Spr. & Name \\
\hline \multirow[t]{3}{*}{$819 / 23$} & Börger/Werpeloh \\
\hline & Klöbertannen \\
\hline & Hedwigestein \\
\hline 826 & Buschhöhe I \\
\hline 825 & Buschhöhe II \\
\hline 829 & Spahn \\
\hline 830 & Hooge Steine (Werlte) \\
\hline \multirow[t]{2}{*}{833} & Pütkesberge \\
\hline & Düvelskuhlen \\
\hline 838 & Kölkesdose \\
\hline 841 & Lahn \\
\hline 842 & North Hüven \\
\hline 843 & Hüven-Sud \\
\hline 846 & Gross Stavern \\
\hline 847 & Klein Stavern \\
\hline 848 & Deymanns Mühle I \\
\hline 849 & Deymanns Mühle II \\
\hline 850 & Deymanns Mühle III \\
\hline 851 & Deymanns Mühle IV \\
\hline 852 & Apeldorn \\
\hline 857 & Gross Berssen \\
\hline \multirow{2}{*}{859} & Hüven/Gross Berssen I \\
\hline & Hüven/Gross Berssen II \\
\hline 860 & Konigsgrab \\
\hline 861 & Wiederherges-teller \\
\hline 863 & Westerloh \\
\hline \multirow{2}{*}{866} & Lähden \\
\hline & Lonenfeld \\
\hline 873 & Radsberg \\
\hline 874 & Thuine \\
\hline 875 & Alt-Frerener \\
\hline 879 & Mehringersteine I \\
\hline 880 & Mehringersteine II \\
\hline 881 & Mehringersteine III \\
\hline 882 & De Smae \\
\hline 883 & Hekese B \\
\hline 884 & Hekese A \\
\hline 885 & Bockraden \\
\hline 886 & Restruper \\
\hline 887 & Dalmmer \\
\hline \multirow[t]{2}{*}{888} & Klein Bokern \\
\hline & Tecklenburg \\
\hline 891 & Meyer \\
\hline 892 & Reinecke I \\
\hline 893 & Reinecke II \\
\hline 894 & Rickelmann I \\
\hline 895 & Grumfeld West I \\
\hline 895 & Grumfeld West II \\
\hline
\end{tabular}

$\begin{array}{ccrrrr}\text { A } & \text { h } & \delta & \text { pass. } & \text { lat. } & \text { long. } \\ 69 & 2 & 10.9 & 164 \frac{1}{2} & 52.89 & 7.50 \\ 55 & 0 & 20.2 & 148 \frac{1}{2} & 52.89 & 7.49 \\ 95 \frac{1}{2} & 1 \frac{1}{2} & -4.5 & - & 52.88 & 7.59 \\ 167 & 0 & -36.0 & - & 52.87 & 7.52 \\ 71 & 1 & 10.5 & 152 \frac{1}{2} & 52.87 & 7.52 \\ 70 \frac{1}{2} & - & 11.6 & - & 52.87 & 7.57 \\ 53 & - & 21.3 & 144 \frac{1}{2} & 52.88 & 7.68 \\ 76 \frac{1}{2} & 0 & 8.1 & - & 52.83 & 7.51 \\ 100 \frac{1}{2} & 0 & -6.3 & 184 \frac{1}{2} & 52.81 & 7.48 \\ 101 & - & -6.9 & - & 52.80 & 7.58 \\ 57 \frac{1}{2} & 0 & 18.9 & - & 52.83 & 7.64 \\ 99 & - & -5.4 & - & 52.79 & 7.55 \\ 128 & 0 & -21.9 & - & 52.78 & 7.56 \\ 94 & 0 & -2.4 & 185 \frac{1}{2} & 52.78 & 7.44 \\ 68 \frac{1}{2} & 0 & 12.8 & - & 52.78 & 7.42 \\ 140 & - & -27.6 & - & 52.77 & 7.43 \\ 84 \frac{1}{2} & - & 3.3 & - & 52.77 & 7.43 \\ 73 & 0 & 10.2 & - & 52.77 & 7.43 \\ 91 \frac{1}{2} & 0 & -0.9 & - & 52.77 & 7.43 \\ 56 \frac{1}{2} & - & 19.5 & 135 \frac{1}{2} & 52.73 & 7.39 \\ 143 & 0 & -28.9 & - & 52.77 & 7.50 \\ 46 \frac{1}{2} & - & 24.6 & - & 52.78 & 7.52 \\ 93 \frac{1}{2} & - & -2.1 & - & 52.78 & 7.52 \\ 80 & - & 6.0 & 187 \frac{1}{2} & 52.78 & 7.52 \\ 75 & - & 9.0 & 157 \frac{1}{2} & 52.78 & 7.52 \\ 90 & - & 0.0 & - & 52.75 & 7.51 \\ 112 \frac{1}{2} & - & -13.4 & - & 52.77 & 7.57 \\ 87 \frac{1}{2} & 0 & 1.5 & - & 52.74 & 7.45 \\ 92 \frac{1}{2} & - & -1.5 & 183 \frac{1}{2} & 52.52 & 7.46 \\ 59 & - & 18.3 & 149 \frac{1}{2} & 52.51 & 7.51 \\ 65 \frac{1}{2} & - & 14.6 & - & 52.50 & 7.55 \\ 58 & 0 & 18.9 & - & 52.38 & 7.32 \\ 27 \frac{1}{2} & 0 & 32.8 & 107 \frac{1}{2} & 52.37 & 7.32 \\ 40 & 0 & 27.9 & - & 52.37 & 7.32 \\ 94 \frac{1}{2} & - & -2.7 & - & 52.64 & 7.69 \\ 135 \frac{1}{2} & - & -25.7 & - & 52.59 & 7.78 \\ 140 & - & -27.7 & - & 52.59 & 7.78 \\ 100 & 1 & -6.9 & 191 \frac{1}{2} & 52.59 & 7.80 \\ 106 \frac{1}{2} & - & -9.9 & - & 52.58 & 7.77 \\ 119 & - & -17.1 & 208 \frac{1}{2} & 52.55 & 7.74 \\ 118 \frac{1}{2} & - & -16.9 & - & 52.54 & 7.76 \\ 47 & 4 & 21.2 & - & 52.20 & 7.79 \\ 57 & - & 19.4 & - & 52.49 & 7.88 \\ 90 \frac{1}{2} & - & -0.3 & - & 52.49 & 7.88 \\ 66 \frac{1}{2} & - & 14.0 & 154 \frac{1}{2} & 52.49 & 7.88 \\ 83 \frac{1}{2} & - & 3.9 & - & 52.49 & 7.88 \\ 62 \frac{1}{2} & 1 & 15.5 & 152 \frac{1}{2} & 52.48 & 7.88 \\ 59 \frac{1}{2} & 1 & 17.2 & - & 52.48 & 7.88\end{array}$


Table 1 cont'd]

\begin{tabular}{|c|c|c|c|c|c|c|c|}
\hline Spr. & Name & A & $\mathrm{h}$ & $\delta$ & pass. & lat. & long. \\
\hline 896 & Grumfeld Ost & $50 \frac{1}{2}$ & - & 22.8 & - & 52.48 & 7.88 \\
\hline 897 & Wiemelsberger & 85 & 1 & 2.6 & - & 52.45 & 7.86 \\
\hline 899 & Horststeine & $87 \frac{1}{2}$ & - & 1.5 & - & 52.40 & 8.08 \\
\hline 900 & Darpvenners I & 77 & - & 7.9 & - & 52.37 & 8.18 \\
\hline 901 & Darpvenners II & $65 \frac{1}{2}$ & - & 14.7 & - & 52.37 & 8.18 \\
\hline 902 & Darpvenners III & $68 \frac{1}{2}$ & - & 12.9 & - & 52.37 & 8.18 \\
\hline 903 & Driehausen & $94 \frac{1}{2}$ & - & -2.7 & - & 52.36 & 8.20 \\
\hline 904 & Felsener Esch I & $105 \frac{1}{2}$ & 1 & -10.2 & - & 52.37 & 8.22 \\
\hline 905 & Felsener Esch II & $31 \frac{1}{2}$ & 1 & 30.4 & - & 52.37 & 8.22 \\
\hline 906 & Duibberorter I & $71 \frac{1}{2}$ & - & 11.2 & - & 52.32 & 8.19 \\
\hline 907 & Dübberorter II & $114 \frac{1}{2}$ & 0 & -14.7 & - & 52.32 & 8.20 \\
\hline 908 & Hehmischsteine & $91 \frac{1}{2}$ & 0 & -0.9 & - & 52.33 & 8.07 \\
\hline 909 & Karlsteine I & $69 \frac{1}{2}$ & 3 & 9.9 & - & 52.32 & 8.04 \\
\hline 910 & Karlsteine II & $74 \frac{1}{2}$ & 4 & 6.2 & - & 52.32 & 8.04 \\
\hline 912 & Karlsteine II & $54 \frac{1}{2}$ & - & 20.8 & - & 52.31 & 8.08 \\
\hline 913 & Ostringer I & $43 \frac{1}{2}$ & - & 26.3 & $135 \frac{1}{2}$ & 52.31 & 8.08 \\
\hline 914 & Teufelsteine & $80 \frac{1}{2}$ & - & 5.8 & - & 52.26 & 8.11 \\
\hline 915 & TeufelsTeigtrog & $102 \frac{1}{2}$ & 1 & -8.4 & - & 52.35 & 8.16 \\
\hline 916 & Teufels Backofen & $82 \frac{1}{2}$ & 0 & 4.6 & $172 \frac{1}{2}$ & 52.35 & 8.16 \\
\hline 917 & Sloopsteine & $65 \frac{1}{2}$ & - & 14.7 & - & 52.31 & 8.20 \\
\hline 919 & Potthoff & $106 \frac{1}{2}$ & - & -10.0 & - & 52.25 & 8.07 \\
\hline 920 & Grettersche-steine & $54 \frac{1}{2}$ & 1 & 21.7 & $144 \frac{1}{2}$ & 52.27 & 8.12 \\
\hline 921 & Sundermann-steine & $38 \frac{1}{2}$ & - & 28.6 & - & 52.28 & 8.13 \\
\hline 922 & Jeggen & $49 \frac{1}{2}$ & - & 23.4 & - & 52.28 & 8.20 \\
\hline \multirow[t]{2}{*}{923} & Deitinghausen I & $86 \frac{1}{2}$ & - & 2.1 & - & 52.29 & 8.30 \\
\hline & Deitinghausen II & $77 \frac{1}{2}$ & - & 7.6 & - & 52.29 & 8.30 \\
\hline 936 & Visbeker Brautigam I & $92 \frac{1}{2}$ & - & -1.5 & - & 52.88 & 8.27 \\
\hline 934 & Visbeker Brautigam II & $87 \frac{1}{2}$ & - & 1.5 & - & 52.88 & 8.27 \\
\hline 937 & Visbeker Brautigam III & $81 \frac{1}{2}$ & - & 5.1 & - & 52.88 & 8.27 \\
\hline 935 & Visbeker Brautigam IV & $104 \frac{1}{2}$ & - & -8.7 & $196 \frac{1}{2}$ & 52.88 & 8.27 \\
\hline 938 & Brautwagen & 67 & - & 13.6 & - & 52.88 & 8.27 \\
\hline 939 & Kellersteine I & 119 & 1 & -17.8 & - & 52.88 & 8.28 \\
\hline 940 & Kellersteine II & $94 \frac{1}{2}$ & 1 & -3.5 & - & 52.88 & 8.28 \\
\hline \multirow[t]{5}{*}{944} & Dötlingen & 82 & - & 4.8 & - & 52.94 & 8.38 \\
\hline & Egypten & $130 \frac{1}{2}$ & - & -23.0 & - & 52.96 & 8.36 \\
\hline & Döhlen/Huntlosen & $61 \frac{1}{2}$ & - & 16.7 & - & 52.98 & 8.24 \\
\hline & & 115 & - & -14.8 & - & 52.93 & 8.24 \\
\hline & Engelmansbake & $71 \frac{1}{2}$ & 0 & 11.0 & - & 52.88 & 8.25 \\
\hline 948 & Glaner Braut I & $95 \frac{1}{2}$ & 0 & -3.3 & - & 52.93 & 8.37 \\
\hline 949 & Glaner Braut II & 41 & 0 & 27.1 & - & 52.93 & 8.37 \\
\hline 950 & Glaner Braut III & $47 \frac{1}{2}$ & - & 24.0 & $146^{\frac{1}{2}}$ & 52.93 & 8.37 \\
\hline \multirow[t]{4}{*}{952} & Visbeker Braut & 39 & - & 27.9 & - & 52.89 & 8.32 \\
\hline & Thölstedt & $87 \frac{1}{2}$ & - & 1.5 & - & 52.88 & 8.34 \\
\hline & Schmeersteine & 48 & 0 & 23.8 & - & 52.88 & 8.33 \\
\hline & Muhlensteine & 39 & 0 & 28.0 & - & 52.87 & 8.33 \\
\hline 954 & Kellersteine I & 82 & - & 4.8 & - & 52.89 & 8.36 \\
\hline 955 & Kellersteine II & 70 & - & 11.9 & - & 52.89 & 8.37 \\
\hline 956 & Hohesteine & 102 & - & -7.2 & $188 \frac{1}{2}$ & 52.90 & 8.38 \\
\hline 958 & Kleinenkneten I & $49 \frac{1}{2}$ & - & 23.1 & $134 \frac{1}{2}$ & 52.86 & 8.43 \\
\hline 958 & Kleinenkneten II & $51 \frac{1}{2}$ & - & 22.1 & $135 \frac{1}{2}$ & 52.86 & 8.44 \\
\hline 958 & Kleinenkneten III & 53 & - & 21.3 & $135 \frac{1}{2}$ & 52.86 & 8.44 \\
\hline
\end{tabular}


Table 1 cont'd]

$\begin{array}{llcrrrrr}\text { Spr. } & \text { Name } & \mathrm{A} & \mathrm{h} & \delta & \text { pass. } & \text { lat. } & \text { long. } \\ 957 & \text { Kleinenkneten IV } & 184 \frac{1}{2} & - & -37.0 & 89 \frac{1}{2} & 52.86 & 8.44 \\ 959 & \text { Teufelssteine } & 92 & - & -1.2 & - & 52.90 & 7.81 \\ 961 & \text { Schlingsteine } & 77 & 0 & 7.8 & - & 52.86 & 7.76 \\ 962 & \text { Hünensteine } & 38 \frac{1}{2} & - & 28.2 & - & 52.84 & 7.76 \\ 968 & \text { Oldendorfer } & 88 \frac{1}{2} & 0 & 0.9 & - & 52.78 & 7.83 \\ 974 & \text { Heidenopter-fisch } & 74 \frac{1}{2} & - & 9.3 & - & 52.88 & 8.27 \\ 978 & \text { Damme I } & 75 \frac{1}{2} & - & 8.8 & 170 \frac{1}{2} & 52.50 & 8.16 \\ 979 & \text { DammeII } & 88 \frac{1}{2} & - & 0.9 & - & 52.51 & 8.16 \\ 980 & \text { Stappenberg } & 58 & 4 & 15.4 & 146 \frac{1}{2} & 52.56 & 8.23 \\ 983 & \text { Kleine Sloopsteine } & 72 \frac{1}{2} & - & 10.6 & - & 52.36 & 7.93 \\ 984 & \text { Grosse Sloopsteine } & 72 \frac{1}{2} & - & 10.6 & - & 52.32 & 7.91 \\ & \text { Urgeschichthches } & 103 \frac{1}{2} & - & -8.2 & - & 52.44 & 7.87\end{array}$

orientation in which the main axis is orientated within the sunrise/sunset or moonrise/ moonset limits for most of the monuments considered here. In fact $85-87 \%$ of the monuments lie inside the solar limits, while $94 \%$ are inside the limits of the moon.

Figure 3, upper right, shows the passage azimuth for the 63 measured passages. The passages are always located in the side of the chamber facing roughly south or east. 56 passages ( $89 \%$ of the total) are outside the sunrise or sunset limits to the south and $49(78 \%)$ are outside the lunar limits. ${ }^{13} 6$ passages $(9.5 \%)$ are located in the eastward area. There is one passage inside the solar limits to the west, although it is quite close to the winter solstice sunset.

In order to interpret these data we must first address the issue of which axis we consider the principal axis of orientation. Several facts lead us to consider the main axis of the chamber to be such. The chamber is always several times larger than the passage and it is thus the most prominent architectural feature. Also, the passage stones are generally smaller than those of the chamber. Finally, the entrance was not always marked by any pair of stones in the original layout. ${ }^{14}$

Another key issue is, which end of the main axis of the chamber should be preferred. This also proves to be quite problematic. Few remains of bones have been found in the chambers of TRB-West monuments. For other TRB groups there is no obvious preference in the orientation of the bodies or the offerings found. ${ }^{15}$ The entrance may give us the clue to the general orientation pattern. For those megaliths with the chamber oriented roughly north-south we prefer the southern end because of the general preference to open the entrances to the south. The entrances for those monuments placed roughly north-south is always in the eastern side. In view of this, we will consider the eastern orientation of the chamber as the preferred one for the monuments aligned east-west.

Figure 3, lower left, shows a histogram of the azimuths for the 163 monuments with the above considerations taken into account. This histogram has been smoothed with a bandpass of $3^{\circ}$ to account for the different error sources. Two distributions are examined. The solid line is calculated taking into account that the northern limit to reverse the orientations to southwest is at the summer solstice sunrise, while the 

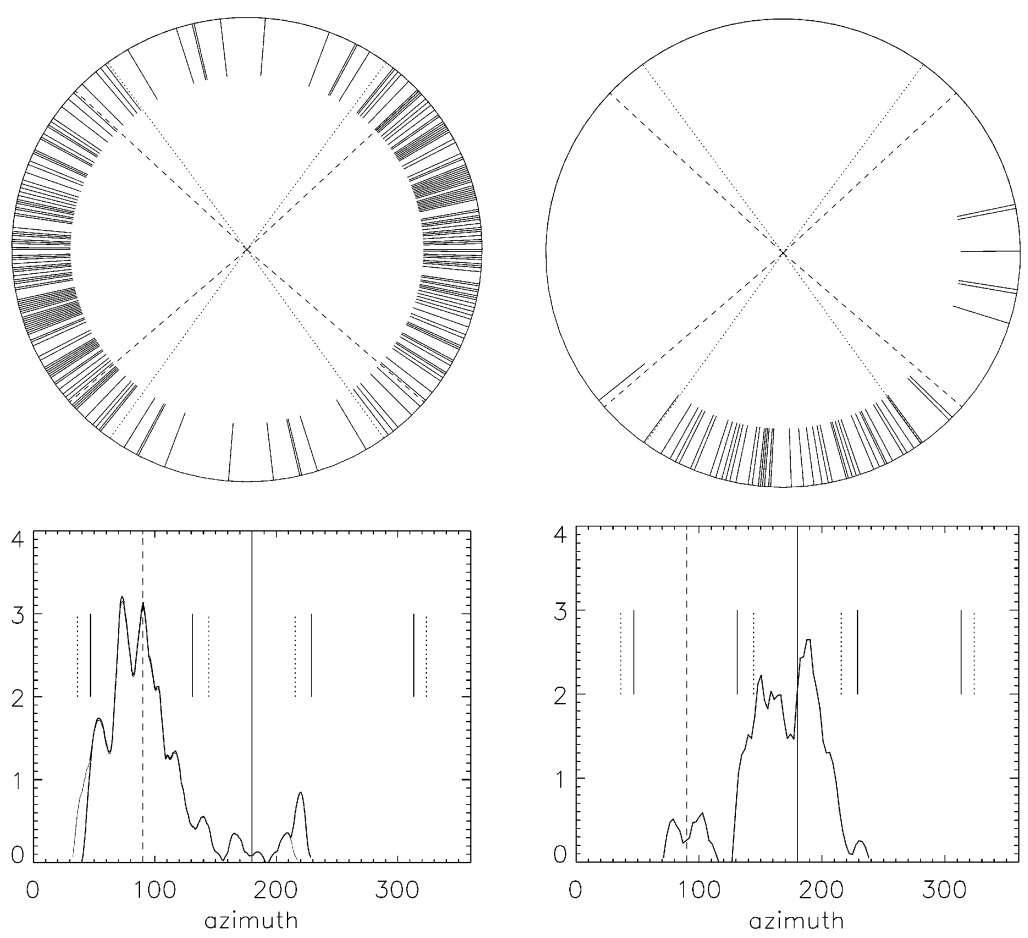

FIG. 3. Distribution of orientations for the 163 megalithic monuments measured in the TRB-West area. (upper left) Diagram for the chamber azimuths. Both ends of the chamber are considered. Dashed lines indicate the solstices and the dotted lines indicate the lunar extreme points. (upper right) The passage azimuths. (lower left) Histogram for the chamber azimuths; only the east and south ends are considered here (see text). The dashed vertical line indicates due east, solid short vertical lines indicate the solstices, and the dotted lines the lunar standstill points. (lower right) Histogram for the passage azimuths.

lighter curve takes this to be placed at the northern major lunar standstill. No big differences are found and we feel that the following discussion is free from spurious effects from this choice. The histogram has been normalized by the mean of the distribution and thus a peak above a value of 3 in the $y$-axis can be considered as highly significant. We find two such peaks, one located almost due east $\left(90^{\circ}\right)$ and the second at azimuth $\sim 70^{\circ}$.

Figure 3, lower right, presents a histogram of the azimuths for the 63 passages. Two main peaks are found, one close to south but not exactly, and a second one near the major southern lunar standstill.

Figure 4 shows the histogram for the declinations of the 163 monuments with a bandpass of $1.5^{\circ}$ to account for the errors in declination. Two distributions are shown, one for a $0^{\circ}$ horizon and another for a $1^{\circ}$ horizon for those monuments listed in Table 


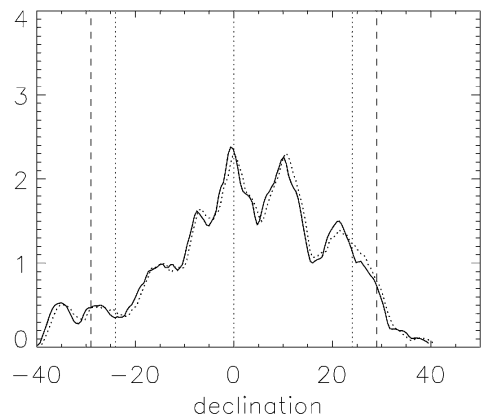

FIG. 4. Distribution of declinations for the 163 passage graves measured in the TRB-West group. Dotted vertical lines indicate the declinations for the equinoxes and solstices and dashed vertical lines indicate the declinations for the major lunar standstill positions.

1 with a dashed line in the altitude (h) column. These distributions are given by the solid and dotted curves in Figure 4. We find very small differences and thus conclude that the results are robust.

Two clear peaks appear in Figure 4, one close to declination $0^{\circ}$ and the second at declination $10^{\circ}$. The fact that monuments located in a well-defined but sizeable area ${ }^{16}$ share a common pattern of orientation, and this in the absence of prominent topographical features, prompts us to propose an astronomical basis for these orientations. We can search for possible 'targets'. A first candidate should be the sun, given that most of the monuments are located within the limits for its rise/climb. ${ }^{17}$ The main peaks could be related to the sun near the equinox (for $\delta=0^{\circ}$ ) and the sun 1 month after/before the equinox (spring/autumn, $\delta=10^{\circ}$ ). ${ }^{18} \mathrm{~A}$ number of monuments are orientated outside the limits of sunrise/sunclimb so that we might naturally think that a second target could be the moon, especially for those monuments beyond the sun's limits to the north. ${ }^{19}$ Then the full moon around the equinox and the full moon one month after autumn equinox could be the possible targets.

\section{Local differences}

Figure 1 shows that the distribution of megaliths is not homogeneous in the region of the TRB-West group. On the contrary, they appear to be clustered around certain areas. One such cluster is the Dutch group studied by González-García and CostaFerrer ${ }^{20}$ along the 'Honds Rug'. A second group can be identified near Meppen, a third around Osnabrück, and a fourth close to Wildeshaussen.

Figure 5 shows the histogram of azimuths for these four clusters. Although the statistics are admittedly low, we find some interesting differences between the various groups. The Dutch cluster (52 megaliths) shows the two peaks, with the one at $70^{\circ}$ slightly more prominent. The two peaks are also clearly visible around Meppen (51 megaliths). However, going to the south (Osnabrück, 29 megaliths), ${ }^{21}$ the peak 

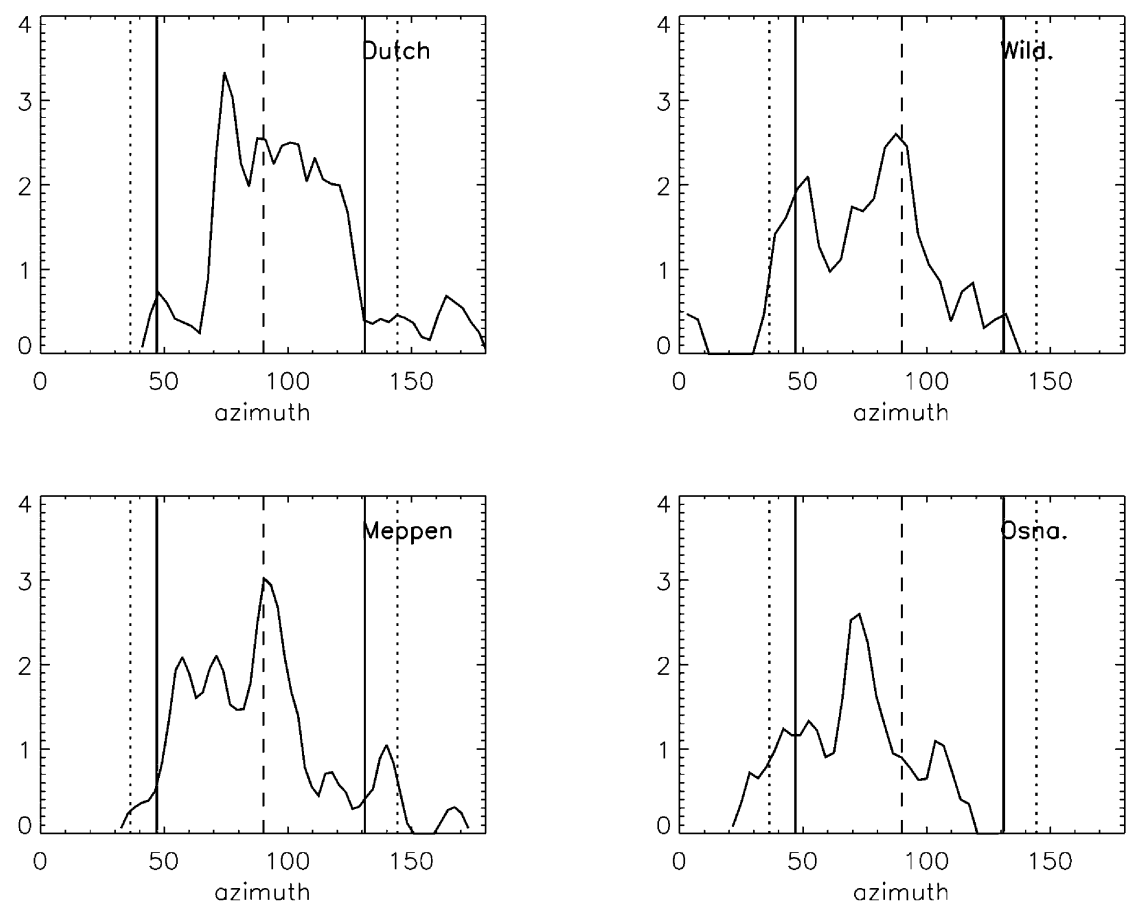

FIG. 5. Regional distributions of orientations in the four clusters described in the text: (upper left) Dutch group; (upper right) Wildeshausen group; (lower left) Meppen group; (lower right) Osnabrück group. Reference lines as in Figure 3, lower.

at $90^{\circ}$ disappears while to the east (Wildeshaussen, 31 megaliths) the $70^{\circ}$ peak is not present.

Hamel measured the orientation of 97 megaliths in the Mecklenburg area. ${ }^{22} \mathrm{~A}$ clear tendency towards east-west is found with no clear signature of a privileged orientation towards $70^{\circ}$, in agreement with our easternmost cluster in Wildeshausen.

TRB-North group measurements do not display a sharp peak at $70^{\circ}$, as we see from the studies by Hard and Roslund and by Henrikson. ${ }^{23}$ In fact, the megaliths of this region are somewhat different to the other areas. The most prominent feature is the passage, and these authors have measured the orientation of this structure. The most relevant peak is found close to the winter solstice sunrise, far from the main peaks found in the TRB-West and Mecklenburg monuments. This seems to point to important local differences in the orientation of the megaliths within the TRB area.

These disparities may arise from different orientation customs. If the orientation has an astronomical origin the disparities could be related to different astronomical phenomena for the distinct areas, as argued above. A further possibility arises, namely, that the monuments were orientated in relation with local trading routes..$^{24}$ We could 
then argue for an interesting archaeotopographical orientation custom involving the megalithic monuments as landscape markers in the trading routes.

\section{Acknowledgements}

We would like to express our gratitude to J. A. Belmonte for stimulating discussions and guidance, and to A. Hänel for his help with literature, his hospitality and for helping us finding our way close to Osnabrück. This work has been partly financed by the Instituto de Astrofísica de Canarias and by the Spanish MEC under Projects P07/93 "Arqueoastronomía" and AyA2004-01010 "Orientatio ad Sidera", respectively.

\section{REFERENCES}

1. M. Midgley, TRB Culture: The first farmers of the north European plain (Edinburgh, 1992), p. xiii; M. O. Baldia, "A spatial analysis of megalithic tombs", Ph.D. dissertation, Southern Methodist University, Dallas, 1995, electronic version available at http://www.comp-archaeology.org/, chap. 1.

2. Midgley, op. cit. (ref. 1), 43.

3. J. A. Bakker, The Dutch Hunebedden: Megalithic tombs of the Funnel Beaker Culture (Ann Arbor, 1992), 40; Midgley, op. cit. (ref. 1), 221.

4. Such as the 'Langebett' formed by a rectangular and long kerb inside of which there is a tumulus where there may be none, one or several chambers, Bakker, op. cit. (ref. 3), 3. For a description of the different types of dolmens in the TRB-West area see M. Fansa, GrossSteingräber zwischen Weser und Ems (Oldenburg, 2000), 8. Ernst Sprockhoff compiled the data for the megaliths in Germany during the twentieth century. We are interested in the volume on Lower-Saxony: E. Sprockhoff, Atlas der Megalithgräber Deutschlands: Niedersachsen, Westfalen (Bonn, 1975).

5. Regional differences appear to be important. TRB-North megaliths have a long and narrow entrance formed by several pairs of stones. The chamber is often shorter than the entrance, and shorter, in general, than in the TRB-West group. For these monuments the entrance can be thought of as the main axis of the structure. C. Tilley, The dolmens and passage graves of Sweden: An introduction and guide (London, 1999), 13.

6. Midgley, op. cit. (ref. 1); Baldia, op. cit. (ref. 1), chap. 1; Bakker, op. cit. (ref. 3), 3. To our knowledge, just one (909 Karlsteine I) of the measured megalithic monuments was made out of quarry stones.

7. Bakker, op. cit. (ref. 3), 3 .

8. Bakker, op. cit. (ref. 3), 3-5.

9. A. C. González-García and L. Costa-Ferrer, "Orientations of the Dutch Hunebedden", Journal for the history of astronomy, xxxiv (2003), 219-26.

10. A. C. González-García and L. Costa-Ferrer, "The orientation of the Hünenbetten of Lower-Saxony", Proceedings of the 12 th annual meeting of SEAC (2006), in press.

11. Sprockhoff, op. cit. (ref. 4).

12. González-García and Costa-Ferrer, op. cit. (ref. 9).

13. It is interesting to note the well-defined limits for the passage orientation, close to the southern solar and lunar limits. The fact that we have measurements only for 63 entrances may bias our results and this prevents us to obtain more general conclusions on this point. However, one could speculate if the important orientation was the entrance and this was placed so that it would be lighted by the sun close to the horizon during winter times. The 6 entrances to the east would be outside this scheme, however.

14. Once the megalithic structure was covered by the tumulus, little could be seen from the outside apart from the entrance. However, the axis of the chamber was probably first determined when laying 
the first stones to build the grave. Also, the capstones were also possibly left uncovered, so that the main axis of the chamber was also visible at its end.

15. Midgley, op. cit. (ref. 1), 443.

16. The most distant monuments are more than $100 \mathrm{~km}$ apart.

17. Michael Hoskin, Tombs, temples and their orientations (Bognor Regis, 2001).

18. G. Henrikson, "Orientation of 140 Swedish passage graves: A megalithic calendar", Proceedings of the 13th annual meeting of SEAC (2006), in press.

19. A. C. González-García, L. Costa-Ferrer and J. A. Belmonte, "Solarists vs. Lunatics: Modelling patterns in megalithic astronomy", Proceedings of the 13th annual meeting of SEAC (2006), in press.

20. González-García and Costa-Ferrer, op. cit. (ref. 9).

21. A similar conclusion can be reached from the data collected for this area by A. Hänel, "Ganggräber bei Osnabrück", electronic version available at http://www.physic.uni-osnabrueck.de/ ahaenel/ megal/osmega.html, although Hänel considers the orientation of the passage as the preferred orientation of the monument.

22. J. Hamel, "Astronomie in Alter Zeit", Vorträge und Schriften der Archenhold-Sternwarte, no. 60 (Berlin 1985); Hamel provides data in 10-degree bins. A similar study with identical conclusions was performed by E. Pasztor and C. Roslund, "Orientation of megalithic tombs in Mecklenburg", Actas del IV Congreso de la SEAC "Astronomía en la Cultura", ed. by C. Jaschek and F. Atrio Barandela (Salamanca, 1997), 227-33.

23. González-García and Costa-Ferrer, op. cit. (ref. 10); Henrikson, op. cit. (ref. 18); B. Hardh and C. Roslund, "Passage graves and the passage of the moon", Acta archaeological Lundensia, viii (1991), 35-43. In the work of Henrikson also there is no sharp maximum at $90^{\circ}$.

24. Megaliths are often found in linear arrangements in the landscape as rows of one of more monuments. They have been related with old mediaeval routes, perhaps linked to older prehistoric roads: J. A. Bakker, "On the possibility of reconstructing roads from the TRB Period", Berichten van de Rijksdenst voor het Oudheikundig, Bodemonderzoek, xxvi (1976), 63-91; Midgley, op. cit. (ref 1), 464-71. A possibility to be studied in the future is the actual orientation of the monuments in relation to the orientation of these routes. 